\title{
Weaning and complementary feeding in preterm infants: management, timing and health outcome
}

\author{
Roberta Barachetti, Elisabetta Villa, Mario Barbarini \\ Neonatal Intensive Care Unit, Sant'Anna Hospital, San Fermo della Battaglia (CO), Italy
}

\begin{abstract}
The introduction of solid food is necessary for any infant in order to provide adequate nutrition because when they grow up milk is insufficient for their nutritional needs. Infants born preterm have increased nutritional requirements. The high nutrient demands as well as the organ immaturity of preterm infants combine to render it difficult to achieve dietary intakes that will allow preterm infants to match their in utero growth rates. Current guidelines for the introduction of solid food to term infants cannot be directly translated to preterm infants. For preterm infants such guidelines are lacking. Based on the limited available evidence, it could be concluded that a corrected age of 3 months (13 weeks) may be an appropriate age to start introducing solid food for most preterm infants.

About celiac disease (CD), gluten may be introduced into the infant's diet anytime between 4 and 12 completed months of age. In children at high risk for CD, earlier introduction of gluten (4 vs 6 months or 6 vs 12 months) is associated with earlier development of CD autoimmunity (defined as positive serology) and CD, but the cumulative incidence of each in later childhood is similar.

Relatively to weaning and allergies, the European Society of Pediatric Allergy and Clinical Immunology and the European Society for Paediatric Gastroenterology Hepatology and Nutrition
\end{abstract}

Correspondence: Roberta Barachetti, Neonatal Intensive Care Unit, Sant'Anna Hospital, via Ravona 20, 22042 San Fermo della Battaglia (CO), Italy.

Tel. +39.031.5859720 - Fax: +39.031.585.9889

Email: roberta.barachetti@asst-lariana.it

Key words: Preterm; Weaning; Feeding; Celiac disease.

Contributions: the authors contributed equally.

Conflict of interest: the authors declare no potential conflict of interest.

Funding: Funded by Merqurio Editore S.r.l., with the unconditional contribution of Nestlè Italiana S.p.A.

Received for publication: 6 November 2017.

Accepted for publication: 15 December 2017.

This work is licensed under a Creative Commons Attribution NonCommercial 4.0 License (CC BY-NC 4.0).

CCopyright R. Barachetti et al., 2017

Licensee PAGEPress, Italy

La Pediatria Medica e Chirurgica 2017; 39:181

doi:10.4081/pmc.2017.181 have produced joint guidelines. They recommend exclusive breastfeeding for 4-6 months or use of hypoallergenic formulas if exclusive breastfeeding is not possible. In addition, The American Academy of Pediatrics recommendations now state that there is no evidence to recommend maternal dietary restrictions during pregnancy or breastfeeding. However, there is no evidence that delaying introduction of solids including allergenic foods after 4-6 months is protective.

\section{Introduction}

The introduction of solid food is necessary for any infant in order to provide adequate nutrition, because when they grow up milk is insufficient for their nutritional needs. Infants born preterm have increased nutritional requirements, especially for energy ${ }^{1}$ protein, ${ }^{1-3}$ long-chain polyunsaturated fatty acids, ${ }^{4}$ iron, ${ }^{5}$ zinc, ${ }^{6}$ calcium and selenium. ${ }^{7}$ As a consequence of preterm birth, these infants generally have limited nutrient stores because they missed the crucial last trimester of pregnancy when there is active transfer and accumulation of nutrients to the fetus as well as a rapid rate of growth. During the last trimester of pregnancy, there is significant fetal growth as well as organ maturation and development. The high nutrient demands as well as the organ immaturity of preterm infants combine to render it difficult to achieve dietary intakes that will allow preterm infants to match their in utero growth rates. Some infants born preterm also have ongoing medical conditions such as chronic lung disease, which further increase nutritional requirements. ${ }^{8}$

Current guidelines for the introduction of solid foods to term infants cannot be directly translated to preterm infants. However, there has been limited research regard the optimal age and type of food to be introduced and whether this period of important dietary change influences later health and development. ${ }^{9}$

The development of good head control is important for the safe eating of solid food. Preterm infants have been observed to have delayed early gross motor development when compared with infants born at term, even after correction for prematurity. 10 Therefore, developmental readiness is an important factor that should be considered prior to commence solid food. In infant feeding, parents are often advised that if a baby with a reduced tongue extrusion reflex can sit in a stable supported position, hold his head up well, open his mouth, and leans forward towards the spoon, then he is developmentally ready for solid food.

In 2008, the European Society for Pediatric Gastroenterology, Hepatology and Nutrition Committee on Nutrition reviewed current knowledge and practices on weaning term infants and concluded that in European industrialized countries, complementary feeding should not be introduced before 17 weeks ( 4 months) and no later than 26 weeks ( 6 months) of age. ${ }^{11}$ 
However, for preterm infants such guidelines are lacking. The only guideline relevant to the introduction of solid food for preterm infants was the advice from the Department of Health in the United Kingdom published in 1994,12 which recommended the introduction of solid food when the preterm infant reaches a weight of $5 \mathrm{~kg}$, has lost the extrusion reflex, and is able to eat from a spoon. Unlike the complementary feeding guidelines for term infants, this guideline does not include an age recommendation.

But a review on this topic highlighted that the preterm infants born at the shortest gestations could be as old as 10 months of uncorrected age before they reach $5 \mathrm{~kg}$ and, thus, may be resistant to have anything but milk in their mouth. ${ }^{13}$ Taking developmental issues into consideration, they suggest that most preterm infants may be ready for solid food between 5 and 8 months of uncorrected age, provided that the infant is at least 3 months of corrected age, i.e. when gross motor development should enable safe eating. Based on the limited available evidence, it could be concluded that a corrected age of 3 months (13 weeks) may be an appropriate age to commence the introduction of solid food for most preterm infants. The earliest born infants at 23 weeks of gestation would have an uncorrected age of 7 months, while those infants born closer to term at 36 weeks of gestation would have an uncorrected age of 4 months. By using the uncorrected age, both ends of the preterm spectrum would be eating solid food within the ideal period from a developmental point of view. Solid food introduction from a corrected age of 3 months ( 13 weeks) would also reduce the potentially increased risk of eczema development. 14 Three months of corrected age is too late in respect to what recommended in a $\mathrm{RCT}^{15}$. However, ensuring optimal nutritional intake from birth in the liquid diet until solid food are introduced will improve nutritional status. Using high-protein, energy- and nutrient-dense food, once solid foods are introduced is important for infants born preterm. Further research is required to provide evidence-based guidelines specifically for preterm infants and studies should investigate immediate as well as longer-term consequences of the pattern and timing of introducing solid food on later health and developmental outcomes. ${ }^{9}$

\section{Weaning and celiac disease}

Celiac disease (CD) is an autoimmune disease caused by a permanent intolerance to the main protein component of oats, wheat, spelled, barley, rye: gluten. Occurring only in people carrying one or more susceptibility genes, $\mathrm{CD}$ affects approximately one to three percent of the general population in most parts of the world. ${ }^{16}$

As regards weaning, in 2008, ESPGHAN issued a recommendation to avoid both early (less than 4 months) and late ( 7 months or later) introduction of gluten, and to introduce gluten while the infant is still being breastfed. Those recommendations were based on observational studies suggesting that this approach to gluten introduction reduces the risk for CD. ${ }^{11}$ But since then, two randomized controlled trials have shown that the age of gluten introduction does not affect overall rates (incidence and prevalence) of $\mathrm{CD}$ during childhood. Earlier gluten introduction causes the disease to present itself at an earlier age. These findings suggest that primary prevention of CD through nutritional interventions is not possible at the present time. ${ }^{17,18}$ Meanwhile, new observational evidence shows no difference in CD risk when gluten is introduced while the infant is still breast-feeding, compared to after weaning. Because of its many other health benefits, breastfeeding is recommended for all infants, regardless of celiac disease risk. The updated recommendations are based on studies of infants with known risk genes for CD. However, because this information is generally not known at the time solid food is introduced, the recommendations apply to all infants. CD risk genes are present in 30 to 40 percent of the general European population, as well as in 75 to 80 percent of children who have a close relative (parent or sibling) with celiac disease. For now, there is not enough evidence to make specific recommendations for infants with a family history of CD.

The European Society for Gastroenterology, Hepatology and Pediatric Nutrition indicates that the timing of introduction of gluten, early (less than 4 months) or late (more than 12 months), does not reduce the likelihood of developing the disease in children at risk (variations in some genes are the major genetic risk factors). Although breast-feeding should be promoted for its other well-established health benefits, neither any breast-feeding nor breast-feeding during gluten introduction has been shown to reduce the risk of CD. Gluten may be introduced into the infant's diet anytime between 4 and 12 completed months of age. In children at high risk for $\mathrm{CD}$, earlier introduction of gluten (4 vs 6 months or 6 vs 12 months) is associated with earlier development of $\mathrm{CD}$ autoimmunity (defined as positive serology) and CD, but the cumulative incidence of each in later childhood is similar. Based on observational data pointing to the association between the amount of gluten intake and risk of $\mathrm{CD}$, consumption of large quantities of gluten should be avoided during the first weeks after gluten introduction and during infancy. The optimal amounts of gluten to be introduced at weaning, however, have not been established and there are no recommendations regarding the type of gluten to be used at introduction. 19

\section{Weaning and allergies}

Infant diet, specifically age of weaning and age at introduction of allergenic food, has long been thought to play a role in food allergy. However, controversy surrounding the relationship between timing of introduction of food and development of food allergy has led to a plethora of inconsistent infant feeding guidelines both between and within countries.

During the first 6 months of life the infant develops the readiness to masticate and swallow solid food. Oral immune tolerance, a state of systemic immune unresponsiveness to ingested allergens, ${ }^{20}$ also develops over the course of the first year of life. There is significant evidence from rodent studies that cessation of suckling results in the alteration and maturation of a number of digestive and absorptive mechanisms including modulation in iron absorption regulatory pathways and increase in gastric acid maturation, ${ }^{21}$ although the relevance of these findings to humans is unclear. In addition, there is a dramatic transition of intestinal microbiota composition during weaning 22 which is reflected in the transitioning nature of stool composition which is seen clinically by change from a more liquid to a more formed stool often termed transitionary stool, followed by establishment of a more adult-like stooling pattern. In infants the initial colonizing bacteria are facultative anaerobes Enterobacteriaceae, coliforms, lactobacilli and streptococci. Colonization with anaerobic genera such as Bifidobacterium, Bacteroides, Clostridium and lactic acid bacteria follows thereafter. ${ }^{23}$ The healthy intestinal microbiota in infancy is characterized by a large Gram-positive bacterial population and significant numbers of Bifidobacteria, mainly Bifidobacteria longum, Bifidobacteria breve and Bifidobacteria infantis. Infant feeding practices including the use of formula $v$ breast milk influence the succession of microbiota colonization, altering the genus, species and species composition, as well as the numbers of bacteria 
that colonize the infant intestinal tract although there remains a controversy around the extent to which breastfed baby stool differs qualitatively from formula fed infants. 24

There is a constant interaction between commensal bacteria in the intestinal lumen and the epithelial and immune cells within the gut, and this continuous interaction is central to the maintenance of oral tolerance. The intestinal epithelium represents the largest interface between the external environment and the internal host milieu and constitutes the major barrier through which molecules can either be absorbed or secreted. Tight junctions between absorptive and secretory cells lining the small intestine appear to play a major role in regulating epithelial permeability by influencing paracellular flow of fluid and solutes. Evidence now exists that tight junctions are dynamic rather than static structures and readily adapt to a variety of developmental, physiological and pathological circumstances and are likely to be substantially modulated through the first year of life in response to a range of dietary and developmental milestones. 25

The WHO recommends exclusive breastfeeding for the first 6 months of life, followed by breastfeeding alongside complementary foods up to 2 years of age. 26

Current guidelines from the Department of Health in the UK recommend exclusive breastfeeding for 6 months and avoidance of potentially allergenic foods (peanuts, other nuts, seeds, milk, eggs, wheat, fish or shellfish) until after 6 months of age. ${ }^{27}$

The European Society of Pediatric Allergy and Clinical Immunology and the European Society of Pediatric Gastroenterology, Hepatology and Nutrition (ESPGHAN) have produced joint guidelines. These recommend exclusive breastfeeding for 4-6 months or use of hypoallergenic formulas if exclusive breastfeeding is not possible. In addition, guidelines from ESPGHAN recommend introducing gluten between 4 and 7 months to reduce the likelihood of developing wheat allergy. ${ }^{11}$

The American Academy of Pediatrics recommendations now state that there is no evidence to recommend maternal dietary restrictions during pregnancy or breastfeeding. For infants at high risk of atopic disease, there is some evidence that exclusive breastfeeding for at least 4 months is protective against cow milk allergy in the first 2 years of life. Atopic dermatitis may be delayed by using hydrolysed formulas instead of cow's milk based formulas early in life. However, there is no evidence that delaying intro of solids including allergenic food after $4-6$ months is protective. ${ }^{28}$

In contrast, Australia, which appears to have one of the highest rates of food allergy in the world 29 is plagued by a plethora of infant feeding guidelines including Australian government guidelines which are essentially WHO compliant but recommend avoiding nuts till 3 years and maternal nut avoidance during pregnancy in the context of a strong family history of nut allergy, a raft of State-based guidelines which are all variations on a theme and the peak allergy specialty body guidelines which until recently were modelled on AAP guidelines although not as extreme with egg introduction recommended at after age 12 months rather than 2 years. ${ }^{30}$

\section{Cow milk allergy}

Cow milk is the most common infant food allergy, affecting 1.4$3.8 \%$ of young children. ${ }^{31}$ It can be either IgE-mediated in nature in which exposure to milk causes an immediate reaction with symptoms such as urticaria, angioedema and/or anaphylaxis or it can be non-IgE-mediated, often manifesting with delayed skin or gastrointestinal symptoms. ${ }^{32}$ A delay in the introduction of cow milk products is associated with an increased risk of atopy at 2 years of age. 33
Since then, prospective studies have been conducted looking at the effects of early introduction of cow milk into infant diets. Infants who were started on cow milk protein formulas within the first 14 days of life were significantly less likely to develop IgE-mediated cow milk allergy in comparison with infants who had cow milk introduced between 105 and 194 days of life. 34 A recent study also showed that avoidance of cow milk by use of an extensively hydrolysed whey formula instead did not have a protective effect in infants in developing atopy (primarily eczema) at 12 months of age. 35,36

\section{Hen egg allergy}

Hen egg allergy is the second most common food allergy with a prevalence rate of approximately $2.5 \% .37$ Several large trials have been conducted which look specifically at early introduction of egg. The Australian Healthnuts cohort demonstrated that a delayed introduction of egg until 10-12 months and in infants older than 12 months were both associated with a significantly increased risk of egg allergy compared to those who were introduced to egg at 4-6 months of age. ${ }^{38}$ This has further been supported by results from the Solids Timing for Allergy Reduction randomized control trial which looked at infants with moderate-to-severe eczema who were introduced to egg from 4 months of age in the form of pasteurized raw whole-egg powder (intervention group). ${ }^{39}$ Although not statistically significant, when this group was compared to the control group who avoided egg (given rice powder instead), a lower proportion of infants in the intervention group (33\%) had a diagnosis of IgE-mediated egg allergy compared to the control group (51\%). ${ }^{40}$ The Starting Time of Egg Protein study was performed on infants aged 4-6 months with no eczema symptoms who were randomized and double-blinded to receive daily pasteurized raw whole-egg powder or a colour-matched rice powder. ${ }^{36}$ All the infants followed an egg-free diet until 10 months at which time cooked egg was introduced to both groups. In the data analysis, there was no difference between the two groups with regards to the development of IgE-mediated egg allergy at 12 months of age, $7 \%$ egg group $v s 10.3 \%$ in the control group (95\% CI: $0.48-1.17, \mathrm{P}=0.20)$. However, in the per-protocol analysis, a lower percentage of infants in the egg group (3\%) had IgE-mediated egg allergy at 12 months of age compared to the control group (9.9\%) (95\% CI: $0.16-0.65, \mathrm{P}=0.002)$. Interestingly, $6.1 \%$ of the children in the egg group had a confirmed allergic reaction to the study powder and had to stop taking it compared to $1.5 \%$ of the control group.

Another recently published study called the Enquiring About Tolerance study, ${ }^{41}$ which was a randomized controlled trial looking at early introduction of six common food allergens at 3 months of age (early-introduction group (EIG)) alongside breastfeeding compared to exclusively breastfed infants (standard introduction group (SIG)), found that the prevalence of egg allergy was significantly lower in the early-introduction group $(1.4$ vs $5.5 \%, \mathrm{P}=0.009)$ in the per-protocol analysis. Egg allergy was confirmed in 3.7\% of the EIG compared to $5.4 \%$ in the $\mathrm{SIG}$ (relative reduction $31 \%, \mathrm{P}=0.17$ ).

Over the last few years, there is an increasing amount of interest and evidence to support the early introduction of potential allergenic foods to aid in the development of oral tolerance 36

\section{Conclusions}

To start weaning, is important to evaluate the baby's neuromuscular development in particular a good head control for the 
safe eating of solid food. Therefore, developmental readiness is an important factor that should be considered prior to commencing solid food. Further research is required to provide evidence-based guidelines specifically for preterm infants and studies should investigate immediate as well as longer-term consequences of the pattern and timing of introducing solid food on later health and developmental outcomes. Over the last few years, there is an increasing amount of interest and evidence to support the early introduction of potential allergenic food to aid in the development of oral tolerance.

\section{References}

1. Tsang RC, Uauy R, Koletzko B, Zlotkin SH. Nutrition of the Preterm Infant. Cincinnati, OH: Digital Educational Publishing; 2005.

2. Hay WW, Thureen P. Protein for preterm infants: how much is needed? How much is enough? How much is too much? Pediatr Neonatol 2010;51:198-207.

3. Zello GA, Menendez CE, Rafii M, et al. Minimum protein intake for the preterm neonate determined by protein and amino acid kinetics. Pediatr Res 2003;53:338-44.

4. Martinez M. Tissue levels of polyunsaturated fatty acids during early human development. J Pediatr 1992;120:S129-38.

5. Berglund S, Westrup B, Domellöf M. Iron supplements reduce the risk of iron deficiency anemia in marginally low birth weight infants. Pediatrics 2010;126:e874-83.

6. Fuller NJ, Bates CJ, Evans PH, Lucas A. High folate intakes related to zinc status in preterm infants. Eur $\mathrm{J}$ Pediatr 1992;151:51-3.

7. Loui A, Raab A, Braetter P, et al. Selenium status in term and preterm infants during the first months of life. Eur J Clin Nutr 2008;62:349-55.

8. McLeod G, Simmer K, Benninger H, et al. Preterm infants with chronic lung disease: are protein and energy intakes after discharge sufficient for optimal growth? J Paediatr Child Health 2010;47:127-33.

9. DJ Palmer, M Makrides M. Introducing solid foods to preterm infants in developed countries. Ann Nutr Metab 2012;60(Suppl 2):31-8.

10. Van Haastert IC, de Vries LS, Helders PJ, Jongmans MJ. Early gross motor development of preterm infants according to the Alberta Infant Motor Scale. J Pediatr 2006;149:617-22.

11. Agostoni C, Decsi T, Fewtrell M, et al. Complementary feeding: a commentary by the ESPGHAN Committee on Nutrition. J Pediatr Gastrenterol Nutr 2008;46:99-110.

12. Department of Health. Weaning and the Weaning Diet. London, UK: HMSO; 1994.

13. King C. An evidence-based guide to weaning preterm infants. Paediatr Child Health 2009;19:405-14.

14. Morgan J, Williams P, Norris F, et al. Eczema and early solid feeding in preterm infants. Arch Dis Child 2004;89:309-14.

15. Marriott LD, Foote KD, Bishop JA, et al. Weaning preterm infants: a randomised controlled trial. Arch Dis Child Fetal Neonatal Ed 2003;88:F302-7.

16. Husby S, Koletzko S, Korponay-Szabo IR, et al. Guidelines for the diagnosis of coeliac disease. J Pediatr Gastroenterol Nutr 2012;54:136-60.

17. Vriezinga SL, Auricchio R, Bravi E, et al. Randomized feeding intervention in infants at high risk for celiac disease. N Engl J Med 2014;371:1304-15.

18. Lionetti E, Castellaneta S, Francavilla R, et al. Introduction of gluten, HLA status, and the risk of celiac disease in children. N Engl J Med 2014;371:1295-303.

19. European Society for Pediatric Gastroenterology, Hepatology, and Nutrition. Gluten introduction and the risk of coeliac disease: A position paper by the European Society for Pediatric Gastroenterology, Hepatology, and Nutrition. J Pediatr Gastroenterol Nutr 2016;62:507-13.

20. Pabst O, Mowat AM. Oral tolerance tofood protein. Mucosal Immunol 2012;5:232-9.

21. Osaki LH, Curi MA, Alvares EP, Gama P. Early weaning accelerates the differ-entiation of mucous neck cells in ratgastric mucosa: possible role of TGFal-pha/EGFR. Differentiation 2010;79:48-56.

22. Manson JM, Rauch M, Gilmore MS. The commensal microbiology of thegastrointestinal tract. Adv Exp MedBiol 2008;635:15-28.

23. Vael C, Desager K. The importance of the development of the intestinal mic-robiota in infancy. Curr Opin Pediatr 2009;21: 794-800.

24. Adlerberth I, Wold AE. Establishmentof the gut microbiota in Westerninfants. Acta Paediatr 2009;98:229-38.

25. Fasano A. Regulation of intercellular tight junctions by zonula occludens toxin and its eukaryotic analogue zonulin. Ann NY Acad Sci 2000;915:214-22.

26. WHO. Nutrition: Exclusive Breastfeeding, 2010. Available from: http://www.who.int/nutrition/topics/exclusive_breastfeeding/en/

27. Department of Health. Weaning: UK Department of Health, 2008. Available from: http://webarchive.nationalarchives. gov.uk/20130105204405/http://www.dh.gov.uk/prod_consum_dh/groups/dh_digitalassets/documents/digitalasset/dh_084 164.pdf

28. Greer FR, Sicherer SH, Burks AW. Effects of early nutritional interventions on the development of atopic disease in infants and children: the role of maternal dietary restriction, breastfeeding, timing of introduction of complementary foods, and hydrolyzed formulas. Pediatrics 2008;121:183-91.

29. Osborne NJ, Koplin JJ, Martin PE et al. Prevalence of challenge-proven IgE- mediated food allergy using populationbased sampling and predetermined challenge criteria in infants. J Allergy Clin Immunol 2011;127:668-76.

30. Koplin JJ, Allen KJ. Optimal timing for solids introduction why are the guidelines always changing? Clin Experim Allergy $2013 ; 43 ; 826-834$.

31. Leonard SA. Debates in allergy medicine: baked milk and egg ingestion accelerates resolution of milk and egg allergy. World Allergy Organ J 2016;9:1.

32. Koletzko S, Niggemann B, Arato A, et al. Diagnostic approach and management of cow's milk protein allergy in infants and children: ESPGHAN GI Committee practical guidelines. J Pediatr Gastroenterol Nutr 2012;55:221-9.

33. Snijders BE, Thijs C, van Ree R, van den Brandt PA. Age at first introduction of cow milk products and other food products in relation to infant atopic manifestations in the first 2 years of life: the KOALA Birth Cohort Study. Pediatrics 2008;122:e115-22.

34. Katz Y, Rajuan N, Goldberg MR, et al. Early exposure to cow's milk protein is protective against IgE-mediated cow's milk protein allergy. J Allergy Clin Immunol 2010;126:77-82.

35. Boyle RJ, Tang ML, Chiang WC, et al. Prebiotic-supplemented partially hydrolysed cow's milk formula for the prevention of eczema in high-risk infants: a randomized controlled trial. Allergy 2016;71:701-10.

36. Du Toit G, Foong RX, Lack G. The role of dietary interventions in the prevention of IgE mediated food allergy in chil- 
dren. Pediatric allergy and immunology Volume 28, Issue 3 May 2017 Pages 222-229.

37. Ramesh S. Food allergy overview in children. Clin Rev Allergy Immunol 2008;34:217-30.

38. Koplin JJ, Osborne NJ, Wake M, et al. Can early introduction of egg prevent egg allergy in infants? A population-bas ed study. J Allergy Clin Immunol 2010;126:807-13.

39. Palmer DJ, Metcalfe J, Makrides M, et al. Early regular egg exposure in infants with eczema: a randomized controlled trial. J Allergy Clin Immunol 2013;132:387-92.

40. Palmer DJ, Sullivan TR, Gold MS, et al. Randomized controlled trial of early regular egg intake to prevent egg allergy. J Allergy Clin Immunol 2017;139:1600-7.

41. Perkin MR, Logan K, Marrs T, et al. Enquiring About Tolerance (EAT) study: feasibility of an early allergenic food introduction regimen. J Allergy Clin Immunol 2016;137:1477-86. 